\title{
artigo $]$
}

\section{Não basta desfilar, tem que vender: (des)encontros entre moda e mercado}

\author{
It is not enough to show, it has to sell: \\ (dis)agreements between fashion and market
}

\section{[ TARCISIO D'ALMEIDA ]}

Doutorando em Filosofia pela FFLCH-USP; pesquisador e professor do curso de moda da Universidade Anhembi Morumbi; pesquisador-associado do Groupe d'Études sur la Mode da Universidade de Paris V, Sorbonne; consultor de moda e crítico especial sobre o tema para a revista World Fashion e para os jornais Folha de S. Paulo e Valor Econômico.

E-mail: tarcisio.dalmeida@gmail.com

[resumo] A moda registra, desde suas origens no Renascimento até a modernidade nos séculos XIX, XX e neste início do XXI, a essência do consumo. A criatividade adquire caráter mercadológico no mundo da moda, seja na esfera simbólico-estética, seja na econômico-financeira, e ela não existe sem uma equação que contrabalanceie a liberdade do ato criativo dos estilistas de alta-costura e do prêt-à-porter - árbitros da "sugestão" de conceitos/tendências à sociedade. Esta, conseqüentemente, força os criadores de moda a se adequarem ao seu público-alvo. Até que ponto uma tendência de moda pode sobreviver independente das regras mercadológicas? Este artigo traça algumas reflexões acerca desse questionamento.

\section{palavras-chave}

moda; tendência; criação; mercado; consumo.

[abstract] The essence of consumption has been translated into fashion since it was created in Renascence until modern times in the XIX and XX Centuries and early in the XXI Century. In fashion world, creativity attains a merchandizing feature both in symbolic-aesthetic and economical-financial dimension and it could not exist without an equation that counterbalances the freedom of creativeness possessed by the high fashion and prêt-à-porter stylists - the arbitrators for concepts/tendencies "suggestions" to the society. This suggestion, in turn, impels the fashion creators to fit themselves to their target. How far could a fashion tendency survive regardless the market rules? This article outlines some insights about this issue.

[key words] fashion; tendency; creation; market; consumption. 
capitalismo". Villaça, retomando o pensamento de Benjamin complementa

mais do que considerar a moda na sociedade capitalista, no sentido de consumo do novo, é necessário pensar que seu sistema abriga outras formas de trocas simbólicas e econômicas. (2007, p. 144)

A existência da moda é justificada por inúmeros fatores de ordem e campo diversos que interagem para compreender a sua importância, complexidade e conseqüente impacto na sociedade. Moderna por excelência, a moda responde por uma gama de possibilidades que articulam estilos nas esferas individual e coletiva, em busca da inserção nos grupos sociais. 0 "vale-tudo" pela satisfação a partir da roupa é observado, historicamente, e justifica a existência da complexa cadeia que compõe o sistema referencial da moda.

Como entender toda essa cadeia que compõe a moda? Profissionais, como jornalistas, produtores, stylists, fotógrafos, empresários, consultores, intelectuais, entre outros, debruçamse sobre o tema, mapeiam estratégias de reflexão e atuação de todos os envolvidos nos processos de criação, produção e consumo de moda, gerando uma maior profissionalização desse mercado. Dessa forma, temos aqui como proposta examinar o impacto da moda na sociedade (de)marcada pelo consumo ${ }^{[1]}$. A expressão "a sociedade de consumo", herdada da década de 1920, sublima a relação entre a moda e o consumo de seus bens, assim, podemos entender a moda como parte integrante do processo de produção e manutenção do sistema capitalista ${ }^{[2]}$. Consideramos que para compreender a complexidade da moda na contemporaneidade e a atual produção ampliada de bens, é necessário refletir sobre: 1) o que é tendência e o que esta gera no imaginário simbólico e material das pessoas e; 2) o que é mercado e qual seu papel no mundo da moda.

\section{Conceituando tendência}

Intimamente atrelados, o conceito de criação e o de assimilação de tendências são peças-chave no processo de produção do mercado da moda. É interessante verificar como se "fabrica" uma tendência. Espécie de sinalizador para a condução do consumo, a tendência para moda é, segundo Walter Benjamin ${ }^{[3]}$, uma "filha dileta do
0 vocábulo "sinalizador" é, portanto, ideal para explicar a importância do que vem a ser a tendência e suas implicações para o consumo nas sociedades, ou seja, que atitudes o consumo da moda gera nos indivíduos, uma vez que a moda está visceralmente ligada à comunicação comportamental.

De acordo com Gilles Lipovetsky ${ }^{[4]}$

o que se chama de 'tendência' da moda, em outras palavras, a similitude existente entre os modelos das diferentes coleções de um mesmo ano (lugar da cintura, comprimento do vestido, profundidade do decote, largura dos ombros), faz muitas vezes crer, erroneamente, que a moda é decretada por combinação deliberada entre os costureiros e confirma a lógica 'aberta' do poder da alta-costura. (1998, p. 98)

Ora, este poder da alta-costura confirma uma espécie de força histórica do mercado do luxo, que é a base da pesquisa criativa para o mercado da moda, como também apontam Bourdieu (1983) e Durand (1988).

Para citarmos alguns exemplos que bem ilustram o referencial criativo de pesquisas de moda contemporânea, recorremos a algumas criações de importantes nomes na moda.

0 estilista britânico Alexander McQueen explora freqüentemente em seu trabalho a idéia de subversão da criatividade da moda, invertendo conceitos estéticos e investigando novas questões formais e de equilíbrio. 0 look da coleção outono/inverno 2003/04 (fig.1) traduz a força da suspensão da idéia de mera destinação mercadológica da criação de moda. 


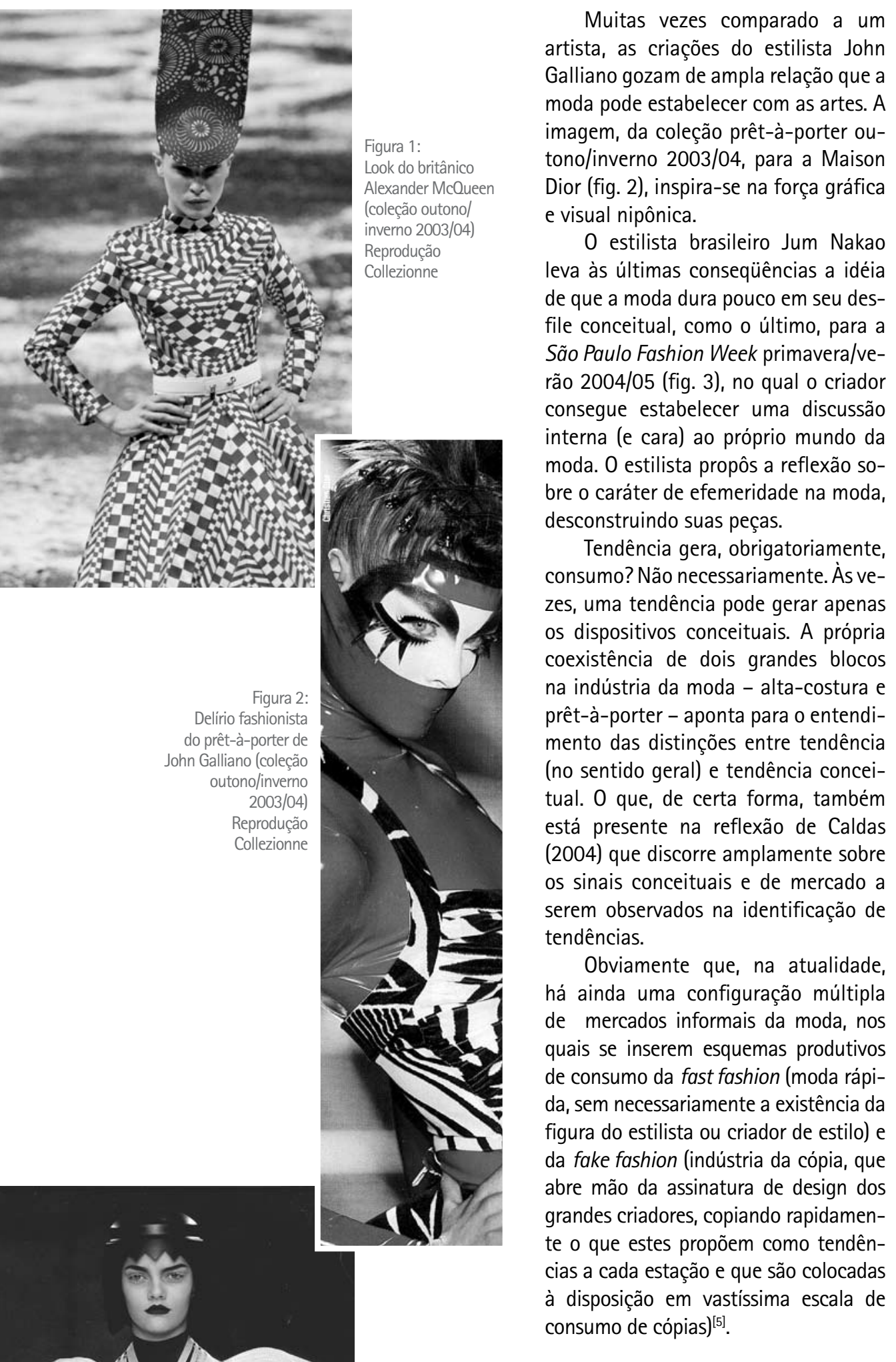


Figura 4: Configuração histórica do mercado da moda a partir de seus segmentos

\begin{tabular}{|c|c|c|c|}
\hline \multicolumn{3}{|c|}{ Mercado da moda } & \\
\hline $\begin{array}{c}\text { Alta-costura } \\
\text { (desde o século XIX) }\end{array}$ & $\begin{array}{c}\text { Prêt-à-porter } \\
\text { (desde o século XX) }\end{array}$ & $\begin{array}{c}\text { Fast fashion } \\
\text { (séculos XX e XXI) }\end{array}$ & $\begin{array}{c}\text { Fake fashion } \\
\text { (séculos XX e XXI) }\end{array}$ \\
\hline $\begin{array}{l}\text { Características: Alto } \\
\text { agregados ao merca } \\
\text { confundem-se com } \\
\text { mercado da moda; } p \\
\text { design de moda; pro } \\
\text { consumo individualiz } \\
\text { São, ao mesmo temp } \\
\text { comerciais. }\end{array}$ & $\begin{array}{l}\text { valores simbólicos } \\
\text { que, muitas vezes, } \\
\text { dutos de luxo do } \\
\text { suem assinatura de } \\
\text { Izem a idéia do } \\
\text { do; e são copiados. } \\
\text { conceituais e }\end{array}$ & $\begin{array}{l}\text { Características: Priv } \\
\text { processo de reprodu } \\
\text { releituras das matri } \\
\text { moda lançadas pelo } \\
\text { grifes; os valores sã } \\
\text { consumo, sem a obr } \\
\text { assinatura de desigr }\end{array}$ & $\begin{array}{l}\text { yiam a rapidez no } \\
\text { ilidade, ou seja, } \\
\text { de tendências de } \\
\text { randes estilistas e } \\
\text { uramente do } \\
\text { toriedade de }\end{array}$ \\
\hline
\end{tabular}

Importante ressaltar que o presente artigo é focado na criação para a alta-costura e no prêt-à-porter e não na análise desses mercados informais. Muitas vezes o processo de concepção de tendências produzidas pelos criadores da alta-costura serve de referência para os estilistas do prêt-à-porter e vice-versa; de maneira que as barreiras da criação atrelam-se a uma espécie de "processo de contaminação", que é muito mais natural do que imaginamos, lembrando que para que ocorra a adequação dessas criações aos seus respectivos públicos-alvo, os estilistas ou grifes de cada um desses segmentos (da alta-costura e do prêt-à-porter) produzem tendências que despertarão o desejo simbólico e/ou materializado.

De fato, esse processo de produção de tendência presente na alta-costura tem na imagem dos grandes criadores uma sustentação essencial: a de árbitros da elegância.

Os costureiros, ao zelarem por afirmar sua singularidade, não podem elaborar suas coleções sem levar em consideração o que aparece de original em seus concorrentes, tendo a moda por vocação surpreender e inventar continuamente novidades. (LIPOVETSKY, 1989, p. 99)
É exatamente a partir dessa idéia que podemos atrelar o caráter de autonomia criativa à moda. Tal criatividade demandará o espírito de liberdade nas produções, sob a égide também das demandas de mercado.

Mesmo atrelada a vários fatores, inclusive ao econômico, a força da criação de moda reside na eficiência do plano simbólico, quando agrega valores que "despertam" o desejo pelas mercadorias "fetiches". Como destaca Benjamin, "a moda é uma agente da mercadoria, prescrevendo o ritual segundo o qual a mercadoria-fetiche quer ser adotada" (apud ROUANET, 1993, p. 25).

A idéia de troca, compartilhada à de dinamismo, alimenta e impulsiona o consumo estético-simbólico da moda e a efetivação de seu consumo mercadológico. Na realidade ocidental, lembra Villaça, "a moda está relacionada tanto com o capitalismo quanto com a expressão de idéias, desejos e crenças em circulação na sociedade" (2007, p. 145). Essas reflexões nos fazem pensar sobre as interlocuções entre a tendência e 0 ato de surpreender (com o inusitado) e de inventar (com o novo e visionário) e desperta-nos para mais um questionamento: ser original gera tendência de moda? De um lado, entende-se o processo criativo como dotado da originalidade; de outro, vislumbra-se um olhar mais crítico que vê o processo criativo a partir da releitura. Para Valerie Steele a criação de moda depende do momento histórico de cada estilista. 
Criação é um processo diferente para diferentes estilistas. Alguns, como John Galliano, voltam-se para o passado em busca de idéias e inspirações, enquanto outros, como Miuccia Prada e Helmut Lang, focam-se na vida moderna. (apud D'ALMEIDA, 1999, p. 13)

A figura 5 revela nosso entendimento sobre a complexidade do processo criativo do mundo da moda. Os elementos não acontecem de forma contínua e estanque, mas sim de maneira aleatória e, possivelmente, simultânea e recorrente. Isso quer dizer que o campo das "idéias" pode ser tanto inicial como também final para instaurar a almejada "tendência" na moda. Além disso, observamos que tendência está ligada a um universo de palavras como "criar", "ineditismo", "inventar" e "surpreender", entre outras. Segundo Oliveira,

0 instante imediato, congelado diante do sujeito, na sua ocorrência aqui e agora, tem antecedentes e posteridades que repropõem tanto o passado como o futuro e desestabilizam o eterno presente. $(2005$, p. 484)

Lipovetsky, por sua vez, alerta para a outra face de uma tendência que

(...) escapaà lógica burocrática pelo fato de que resulta também das escolhas da clientela e, depois da Segunda Guerra

Mundial, das escolhas da imprensa, que se voltam num dado momento para tais ou tais tipos de modelo, a 'tendência' revela tanto o poder das paixonites do público ou da imprensa quanto o dos costureiros, que são obrigados, sob pena de fracasso comercial, a acompanhar o movimento, a adaptar-se aos gostos da época. (1989, p. 99)

A configuração atual do mercado da moda mescla a liberdade criativa dos estilistas com a necessidade de adequação ao mercado consumidor. Os inúmeros atores que concebem as "realidades" do processo de criação da moda talvez nem percebam a complexidade dessas etapas do ato criativo e a sua não-linearidade. Criam, produzem e vendem sonhos de moda para um mercado que, de acordo com seu padrão de consumo e de estilo, compra delírios de tendência de moda desses interlocutores.

\section{(Des)encontros e distinções de mercado}

As sociedades modernas confirmam sua produção material de bens de consumo por meio da existência de um mercado, que faz com que a produção seja absorvida pelos indivíduos com a prática do consumo em si. Mais que isso, o mercado de moda opera com mecanismos que ultrapassam esta simples definição.

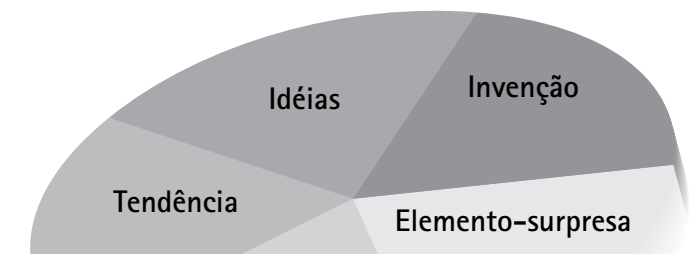

Criação 
Podemos verificar que na primeira fase da Revolução Industrial, no século $X V I I I$, a idéia propulsora de consumo era a de massa, o princípio deliberado com a produção do setor de vestuário era, de certa forma, amplo e irrestrito no sentido de que não havia o alto valor agregado à mercadoria, mas sim a idéia de ampliar o número de produção/consumo dos produtos industrializados. Um século depois, no segundo estágio da Revolução Industrial, instaurou-se uma certa volta ao sistema de produção artesanal, agora autoral, já que tal produção distinguia-se exatamente pelo endereçamento/assinatura de tais produtos que mostravam determinada procedência, no caso dos grandes costureiros da alta-costura, evidenciando a construção de roupas sob medida. De certa forma, podemos dizer que a estratégia de consumo passou da posição de consumo coletivizado (consumo de massa da primeira Revolução Industrial) para o consumo individualizado. A partir da segunda metade do século $X X$, com o surgimento, efetivação e progressiva valorização do prêt-à-porter na moda, consolidouse a democratização da moda pelo "pronto para usar", processo originário no século XVIII nas estratégias de ampliação do consumo motivado pela Revolução Industrial, mas que não se encontrava até então bem-aceito pelas diferentes classes sociais.

Essa discussão sobre as inter-relações entre moda, tendência e mercado tomou lugar aqui objetivando uma possibilidade de conceituação para melhor compreender o que são e como se estruturam valores para o mercado da moda. 0 que nos leva a pensar que não basta criar e desfilar as propostas de moda, é preciso vender tais criações no mercado que, por sua vez, deve ser entendido em sua dinâmica que privilegia modos de produção e consumo diferenciados, segundo momentos históricos e sociais e que é, no caso da moda, (de)marcado pela efemeridade e busca constante pelo "novo" nas sociedades modernas e contemporâneas.

\section{A vez do mercado de moda}

Como entender o mercado de moda, por excelência ansioso por novidades, e a produção de demandas de consumo alinhadas ao desejo individualizado? Há autores, como Benjamin (apud ROUANET, 1993), Baudrillard (1996), Lipovetsky (1989) e Santaella (2004), que ressaltam o forte vínculo da moda com o capitalismo nas sociedades modernas, apontando-a como importante fonte propulsora de riqueza do capitalismo. Esses autores discutiram como a era da modernidade requisitou das sociedades mudanças de comportamento e do padrão de consumo desde a primeira Revolução Industrial, ultrapassando, portanto, a idéia de consumo coletivizado no mercado para o consumo individualizado.

Desse modo, temos uma outra compreensão da força do mercado de moda contemporâneo e suas intersecções que apresentam não somente bens produzidos por grifes prestigiadas da alta-costura e do prêt-à-porter que gozam do atributo conceitual, mas os grandes estilistas e as grandes grifes tanto da alta-costura como do prêt-àporter possuem algumas especificidades na produção de suas criações e no atendimento das demandas de seus distintos públicos-alvo que visam, obviamente, o consumo de suas criações.

A verve dos criadores conceituais faz com que privilegiem as veiculações de "idéias" em detrimento da venda dos produtos. Para melhor compreensão, podemos recorrer à campanha 

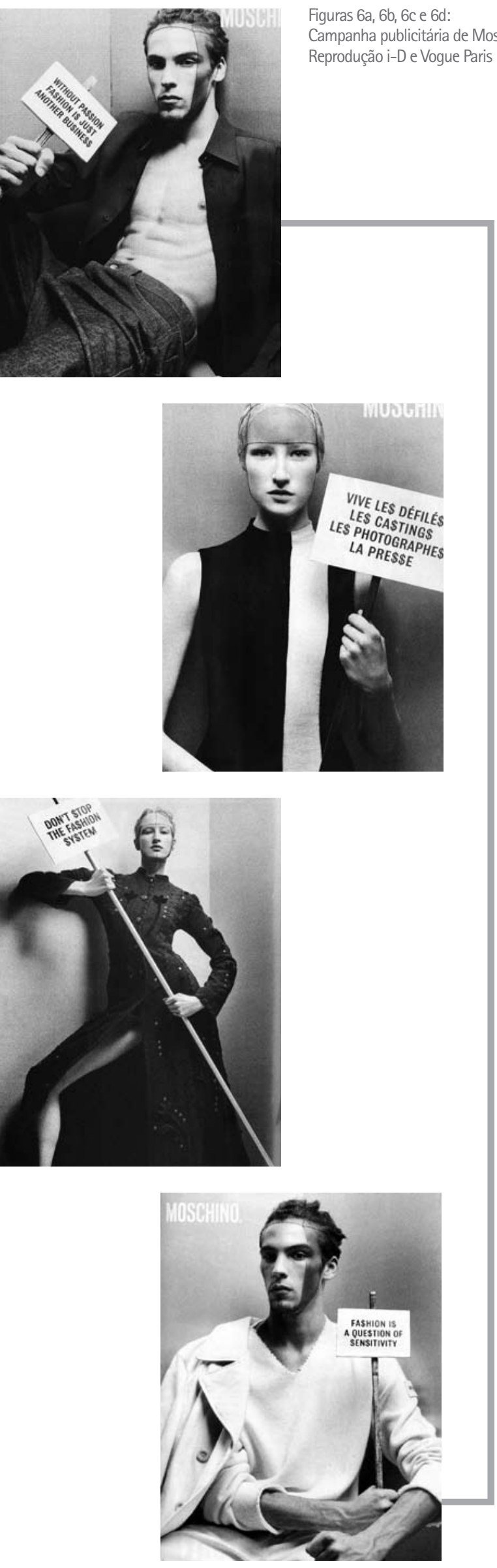

publicitária da grife italiana Moschino (figuras 6a, 6b, 6c e 6d), veiculada mundialmente no ano de 1999, em que a mensagem central reside no estabelecimento de um discurso pró-ato criativo do mundo da moda, repelindo a mera adequação e imposição de regras do mercado às criações dos estilistas, ou seja, a defesa do espírito criativo da moda diante da dominação mercadológica. Os slogans "Sem paixão a moda é apenas mais um negócio", "Viva os desfiles, os castings, os fotógrafos, a imprensa", "Não pare o sistema da moda", "Moda é uma questão de sensibilidade" e "A moda necessita de inspiração constante" traduziam esse posicionamento da grife.

Importante destacar que se não se pode consumir uma peça com grande valor simbólico agregado da alta-costura ou mesmo do prêt-à-porter, busca-se tal satisfação pela força da marca, via aquisição de um perfume ou de um acessório, estratégias que as grandes marcas têm utilizado inteligentemente para ampliar seu público-alvo e incrementar suas vendas. Isso explica a grande expansão dos negócios dos conglomerados do mundo da moda e do luxo (fig. 7). 
Figura 7: As marcas/grifes tops do mercado de moda e de luxo (valores das marcas em bilhões de dólares)

\begin{tabular}{|c|c|c|c|c|}
\hline $\begin{array}{l}\text { Posição no Mercado } \\
\text { Mundial da Moda } \\
\text { em } 2007\end{array}$ & $\begin{array}{l}2007 \\
\text { (US\$) }\end{array}$ & $\begin{array}{l}2006 \\
\text { (US\$) }\end{array}$ & Marca & Pais \\
\hline 1 & 20.415 & 19.579 & Louis Vuitton & França \\
\hline 2 & 12.004 & 10.897 & Nike & EUA \\
\hline 3 & 7.697 & 7.158 & Gucci & Itália \\
\hline 4 & 7.045 & 6.392 & L'Oreal & França \\
\hline 5 & 5.830 & 5.156 & Chanel & França \\
\hline 6 & 5.481 & 6.416 & Gap & EUA \\
\hline 7 & 5.165 & 4.235 & Zara & Espanha \\
\hline 8 & 4.767 & 4.290 & Adidas & Alemanha \\
\hline 9 & 4.255 & 3.854 & Hermès & França \\
\hline 10 & 4.003 & 3.819 & Tiffany & EUA \\
\hline 11 & 3.852 & 3.360 & Cartier & França \\
\hline 12 & 3.287 & 2.874 & Prada & Itália \\
\hline 13 & 3.221 & 2.783 & Burberry & Grã-Bretanha \\
\hline 14 & 3.046 & - & Ralph Lauren & EUA \\
\hline
\end{tabular}

Adaptação a partir da lista 100 Top Brands in the World da revista Business Week. Fonte: Business Week, 6 de agosto de 2007. pp. 59-64.

Lipovetsky pontua brilhantemente essa transição.

Com a moda total, a astúcia da razão é chamada como nunca ao pódio da história: sob a sedução operam as Luzes, sob a escalada do fútil prossegue a conquista plurissecular da autonomia dos indivíduos. (1989, p.158)

Atendo-se aos três tópicos mencionados pelo autor, podemos contemplar o contexto que serve de conceituação de mercado para a vida econômico-social no Ocidente desde o fim do século XIX e que se prolonga até nossos dias, estabelecendo a seguinte equação:

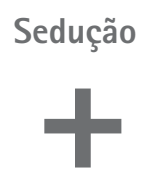

Escalada do Fútil

Autonomia dos Indivíduos
Esse esquema funciona como essencial para compreendermos, sobretudo, o mercado da moda. Ainda, segundo Lipovetsky, "a elevação do nível de vida, abundância das mercadorias e dos serviços, culto dos objetos e dos lazeres, moral hedonista e materialista etc." (1989, p.159) servem como pistas para mapear a sociedade de consumo na era do consumo exacerbado. Ora, conforme alertamos anteriormente, a moda é reflexo da "sociedade de consumo" e como símbolo da atualidade estabelece uma dinâmica perversa de realimentação de tendências para elevar a capacidade de consumo, de tal maneira que o processo de sedução da moda possa direcionar um crescimento acelerado do consumo fútil sem mera necessidade estético-funcional só para justificar a autonomia de cada um perante a sociedade. 
da moda instaura-se, do ponto de vista histórico-econômico, respectivamente, com a alta-costura e o prêt-à-porter. De acordo com Lipovetsky

Portanto, alguns pressupostos são indispensáveis para compreender como opera o mercado da moda: 1) a idéia de produção, ou seja, a oferta de criações da moda; e 2) a idéia de consumo, ou seja, a quem se dirige a demanda por tais criações. Lipovetsky ressalta que

a sociedade centrada na expansão das necessidades é, antes de tudo, aquela que reordena a produção e o consumo de massa sob a lei da obsolescência, da sedução e da diversificação, aquela que faz passar o econômico para a órbita da forma moda. (1989, p.159)

Desse modo, estabelecemos mais uma equação relacionando a diversificação com a sedução e a obsolescência.

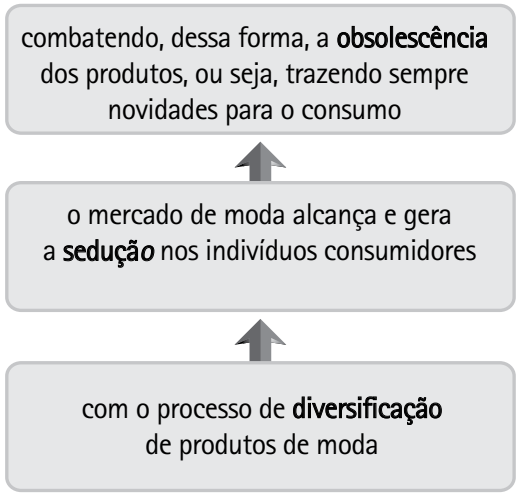

Com a extrema busca do consumo por novidades, tão diferenciado no mercado de moda graças ao avanço tecnológico propiciado desde a Revolução Industrial e ainda com o desenvolvimento constante de fios e fibras têxteis tecnológicas, esse mercado pontua e responde às necessidades por satisfação do eu para a inserção no coletivo. Sendo assim, não somente a esfera econômica justifica esse mercado.

Regulação do mercado de moda

A idéia de incremento na produção e expansão do consumo no mercado de moda oriunda da democratização
Iniciativa e independência do fabricante na elaboração das mercadorias, variação regular e rápida das formas, multiplicação dos modelos e séries - esses três grandes princípios inaugurados pela alta-costura não são mais apanágio do luxo do vestuário, são o próprio núcleo das indústrias de consumo. (1989, p. 159)

Esse posicionamento, que alinha toda a cadeia de produção e consumo na indústria têxtil e da moda, imprime uma certa lógica de produção que serve como emblema indispensável para o conseqüente consumo no mercado da moda, contemplado pelo seguinte percurso programático da cadeia produtiva na indústria têxtil:

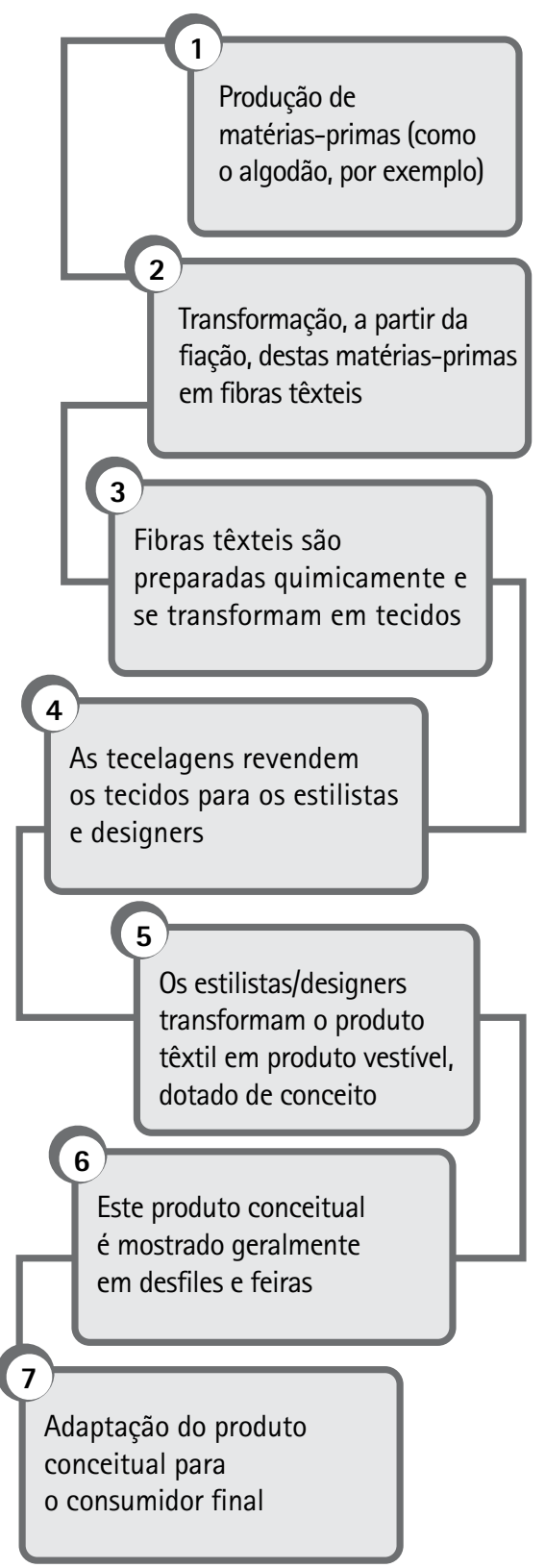


Vale lembrar que Lipovetsky trabalha bastante o conceito de moda consumada para explicar sua temporalidade e efemeridade no mercado com o advento da era das sociedades modernas. Dessa forma, o processo de criação de tendências no mercado da moda fica atrelado a mais dois elementos, a temporalidade e a sazonalidade, produzindo uma espécie de "aceleração da criatividade".

Portanto, na cadeia produtiva do mercado da moda, todos os agentes operam em função da contemplação de uma agenda produtiva que responda à sazonalidade para o conseqüente consumo. A justificativa dessa aceleração na lógica econômica no processo de produção e consumo tem, como vimos, matizes históricas. Essa lógica "realmente varreu todo o ideal de permanência" lembra-nos Lipovetsky (1989, p.160), ao afirmar que agora "é a regra do efêmero que gover- na a produção e o consumo dos objetos". Dessa maneira, a palavra temporalidade passa a ser o passaporte para entendermos essa regra no processo de produção.

Doravante, a temporalidade curta da moda fagocitou o universo da mercadoria, metamorfoseado, desde a Segunda Guerra Mundial, por um processo de renovação e de obsolescência 'programada' propício a revigorar sempre mais o consumo. (LIPOVETSKY, 1989, p.160)

E é justamente a justaposição destes termos que explica a fremente busca pelas tendências para o consumo no mercado da moda, mas que, antecedente a este, devemos nos lembrar sempre da força preponderante do mercado das idéias; este sim funcionando como um (ir)regulador do ato criativo no mundo da moda.

\section{Notas}

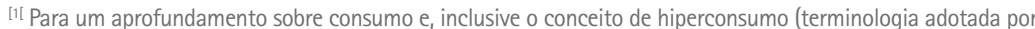
Lipovetsky), sugerimos ver: Baudrillard, Jean. A sociedade de consumo. 2a. ed. Lisboa: Edições 70, 2007. Featherstone, Mike. Cultura de consumo e pós-modernismo. São Paulo: Studio Nobel, 1995. Lipovetsky, Gilles. A sociedade paradoxal - ensaio sobre a sociedade de hiperconsumo. São Paulo: Companhia das Letras, 2007.

${ }^{[2]}$ Claro que não pretendemos analisar o julgo de valor benéfico ou maléfico resultante com o capitalismo, mas sim os dispositivos de construções de relações entre moda e conseqüente crescimento de mercado nas sociedades ocidentais.

${ }^{[3]}$ Filósofo e crítico alemão, nasceu em Berlim, em 1892, e morreu em Port Bou, em 1940. Depois de estudar na capital alemã, em 1918 graduou-se em Berna com a tese intitulada Der Begriffder Kunstkritik in der Deutschen Romantik ( 0 conceito de crítica de arte no romantismo alemão). Sua produção intelectual também alcançou a moda. A célebre citação "A moda é filha dileta do capitalismo" integra os ensaios do autor sobre o tema, produzidos na primeira metade do século XX. A força de seu pensamento crítico gerou um impacto significativo nos estudiosos da moda.

${ }^{[4]} 0$ pensamento desse autor, nascido em Millau, na França, dividiu a comunidade intelectual francesa em dois blocos, entre os anos 1980 e 1990. Por um lado, criou uma fúria e, por outro, uma legião de admiradores de sua produção intelectual. Publicou livros que são registros exatos da questão da individualidade na era moderna. Crédulos e incrédulos comentaram suas obras. 0 seu livro L'Empire de l'éphémère - la mode et son destin dans les sociétés modernes (0 Império do efêmero - a moda e seu destino nas sociedades modernas) influencia, até hoje, gerações pela sua visada e contundente crítica da moda na modernidade.

[5] Para um melhor aprofundamento sobre a configuração desses mercados informais da moda, sugerimos o artigo de: Reinach, Simona Segre. "China and Italy - fast fashion versus prêt-à-porter. Towards a new Culture of fashion" Fashion theory - the journal of dress, body \& culture, vol. 9, issue 1, march 2005. pp. 43-56.

\section{REFERÊNCIAS}

BAUDRILLARD, Jean. A troca simbólica e a morte. São Paulo: Loyola, 1996. pp. 109-130.

BOURDIEU, Pierre. Questões de sociologia. Rio de Janeiro: Marco Zero, 1983. pp.154-161.

CALDAS, Dario. Observatório de sinais - teoria e prática da pesquisa de tendências. Rio de Janeiro: Senac, 2004.

D'ALMEIDA, Tarcisio. Das passarelas às páginas - um olhar sobre o jornalismo de moda. Dissertação (Mestrado) - Escola de Comunicação e Artes, Universidade de São Paulo, 2006.

. Revista traduz o mundo 'fashion'. Folha de S. Paulo, 30 de julho de 1999. p.13.

DURAND, José Carlos. Moda, luxo e economia. São Paulo: Babel Cultural, 1988.

LIPOVETSKY, Gilles. O império do efêmero - a moda e seu destino nas sociedades modernas. São Paulo: Companhia das Letras, 1989.

OLIVEIRA, Ana Claudia de. Espaços-tempos (pós-)modernos ou na moda, os modos. In: GUINSBURG, J.; BARBOSA, Ana Mae (org.). 0 pós-modernismo. São Paulo: Perspectiva, 2005. pp. 473-531.

ROUANET, Sérgio Paulo. A razão nômade - Walter Benjamin e outros viajantes. Rio de Janeiro: UFRJ, 1993. pp. 25-26. 